\title{
Diskussionen bereichern
}

_ „Nicht Sieg sollte der Sinn der Diskussion sein, sondern Gewinn.“ Diese Worte des französischen Schriftstellers Joseph Joubert scheinen die meisten Physiotherapeuten verinnerlicht zu haben. Während meiner Zeit „am Patienten“ fiel mir immer wieder auf, dass die wenigsten meiner Kollegen bei fachlichen Diskussionen auf ihrer Meinung beharten. Selten versuchte einer, um jeden Preis Recht zu behalten. In diesem Verhalten spiegelt sich die Dynamik der Therapie wider. Denn die Arbeit mit Patienten kann nur erfolgreich sein, wenn man als Therapeut bereit ist, seine Perspektive zu wechseln, sich selbst in Frage zu stellen, Fehler und Schwächen einzugestehen und auch mal die Richtung zu ändern, sobald man merkt, dass man in einer Sackgasse gelandet ist. Engstirnigkeit, Verbissenheit und Rigidität haben in der physiotherapeutischen Behandlung keinen Platz.

- Diese Offenheit gegenüber anderen Meinungen und Blickwinkeln findet sich auch in unserem Leserforum auf Seite 6-10: Die Therapeuten haben sich viel Zeit genommen und Leserbriefe zu den Themen geschrieben, die ihnen am Herzen liegen. In den Briefen loben sie, fragen nach und regen an, sie gestehen ein - und sie sind aufgeschlossen gegenüber Kritik. Das hat mich sehr gefreut. Denn wenn zwischen Physiotherapeuten ein solch offener Austausch mit konstruktiver Kritik stattfindet, entstehen neue Ideen. Und die braucht es, damit sich Therapien und Therapeuten immer weiter verbessern können.

_ Ich wünsche Ihnen viel Gewinn beim Diskutieren.

\section{PHYSIOBONUS}

physiobonus heißen die Gewinnspiele in physiopraxis. Wer teilnehmen möchte, nutzt das Formular unter www.thieme.de/ physioonline in der Rubrik physioexklusiv. Und das gibt es in dieser Ausgabe zu gewinnen:

Kursplatz

1 Kurs

„Grundkurs Pilates P-F“ Seite 37

1 Kurs

„Grundkurs Brügger“ Seite 48

Bücher

3-mal „Lonely Planet

Bangladesh“

Seite 39

5-mal „Herzsport“

Seite 42

und außerdem

2 Volleybälle

Seite 26

1 Schultergelenkmodell Seite 46

3 Download-Versionen „Aushangpflichtige Gesetze 2010“ Seite 50

3 Eintrittskarten für das 3. Forum Heilpraxis Seite 56 